\title{
Computer technology: Index to articles in Behavior Research Methods, Instruments, \& Computers from 1977 to 1987
}

\author{
JOSEPH B. SIDOWSKI and GWENDOLYN E. CAMPBELL \\ University of South Florida, Tampa, Florida
}

This issue of the journal provides an index to the computer technology articles published in Behavior Research Methods, Instruments, \& Computers from the beginning of 1977 through October 1987. Articles are listed under the various categories in the form of complete reference citations, except for the journal name. If an article is relevant to several topics, a complete citation is provided for each. If two or more categories contain related material, the Topic Guide refers the reader to the related topics.

The Topic Guide lists the categories and subcategories as they appear serially in the Computer Technology Index. 